\title{
Poéticas quechuas: Garcilaso, Guamán Poma y Anchorena
}

\author{
Gonzalo Espino RelucÉ \\ Universidad Nacional Mayor de San Marcos
}

\begin{abstract}
Resumen
El objeto de este artículo es identificar el contexto y las premisas de las poéticas quechuas de connotados intelectuales como Garcilaso, Guamán Poma y Anchorena. Suma a este interés el de saber cómo funciona cada una de ellas y la tradición a la que se deben. Luego, el artículo se centra en la Gramática Quechua de Anchorena, publicada en 1837, trabajo que rinde tributo a las descripciones hechas por Garcilaso sobre la poesía quechua.

Palabras claves: Poética quechua, Etnopoética, Garcilaso, Guamán Poma, Anchorena.
\end{abstract}

\begin{abstract}
Quechua poetics: Garcilaso, Guaman Poma and Anchorena

The context and premises guiding Quechua Poetics of outstanding writers, and also their functioning and the tradition backing them, are here identified in this study. Besides, this article comments on Anchorena's Gramatica Quechua, and his laudatory expressions when treating Garcilaso's ideas about Quechuan poetry.

Key words: Quechua Poetics, Ethnopoetics, Garcilaso, Guaman Poma, Anchorena.
\end{abstract}




\section{Garcilaso: La lírica quechua y la poética renancentista}

Con la aparición de los Comentarios Reales de los Incas (1609) del Inca Garcilaso de la Vega se instaló en el imaginario letrado una forma de comprender la poesía quechua basada en la estructura métrica y no en la estructura rítmica o en los sentidos que construyen las palabras. ${ }^{1}$ El Inca Garcilaso lee las producciones poéticas indígenas como si estuviese leyendo la poesía renacenticista de la Europa del siglo xvII con aquello que la ciudad real conoce como poesía. Así lo expresa en "La poesía de los Incas Amautas, que son filósofos, y harauicos, que son poetas». (Libro Segundo, XXVII; 1609 / 1985: 87-90) El mestizo asienta que:

De la poesía alcaçaron otra poca, porque supieron hazer versos cortos y largos, con medida de sílabas: en ellos ponían cantares amorosos con tonadas diferentes como se ha dicho. [...] Los versos eran pocos, porque la memoria los guardasse, empero muy compendiosos, con cifras; todos eran sueltos. Por la mayor parte semejavan a la natural compostura española que llaman redondillas (Garcilaso Inca, 1609/ 1985: 87).

En el pensamiento de Garcilaso hay tres postulados que presiden lo que he anotado: Uno, la poesía como potestad de las elites cultas no es un asunto de los indios comunes, sino de los señores curacas y el inca. Es en buena cuenta una práctica cultivada por la elite inca. Dos, en estas estructuras poéticas los incas utilizan "versos cortos y largos, con medida de sílabas», un metro semejante a la redondilla, en especial, la española. Y tres, los temas son los mismos que abordan los poetas hispanos, por lo que, en el esquema garcilasiano, la poesía se compara y homologa con la producción clásica, y se asemeja, en consecuencia, con el horizonte cultural de la Corona.

Esta manera de comprender la poética inca se generalizó y repitió como forma canónica y se divulgó a través de los manuales o versiones acríticas. (cf. Anchorena 1874; Lara 1947; Florián 1980) Se repitió sin detenerse en las estrategias narrativas y poéticas que cada forma discursiva indígena acusaba. A partir de la divulgación de la Nueva coronica i buen gobierno de Phelipe Guamán Poma de Ayala ocurrida en la década del 70 del siglo pasado, se incorporan un conjunto de imágenes de la vida y cultura de los indígenas de las tierras del Inca y sus confrontaciones con los hispanos. ${ }^{2}$ Fue una relectura progresiva 
que pasó de la descalificación a la conformación del indio ladino que presenta un retrato menos idílico, más complejo y extremadamente efectivo, en el que las lenguas y dibujos se interceptan para dar cuenta de la azarosa vida de los indios y la frustración indiana.

\section{Guamán Poma: poesía y ritual}

Con los escritos de Guamán Poma se reubica el discurso andino quechua. Un texto está siempre precedido del ritual que los acompaña, no son enunciados letrados, sino constituye un tejido discursivo cuya unicidad dialógica incorpora voz y cuerpo, habla y espacio, lengua y tiempo, palabra y cosmovisión, lenguajes que le dan forma. Esto explica el fracaso de la difusión de los textos poéticos quechuas. Las diversas antologías de poesía quechua han cercenado esta pauta de lectura. Han occidentalizado las poéticas indígenas (Basadre, 1938; Romualdo, 1984; Bendezú, 1980 y 2003; Arguedas, 1986; Montoya 1987 y 1998).

Si observamos la imagen (Figura $\mathrm{N}^{0} 1$ ) se tiene que el acto poético está emparentado a los rituales indígenas. El inca canta como lo hace con la puca llama y ambos comienzan a repetir. Obviar este dato, sería abandonar las estrategias que hacen del texto un asunto más intenso, rico de significado además de la propia textualidad, por lo que, como veremos, se trata de una conceptualización distinta:

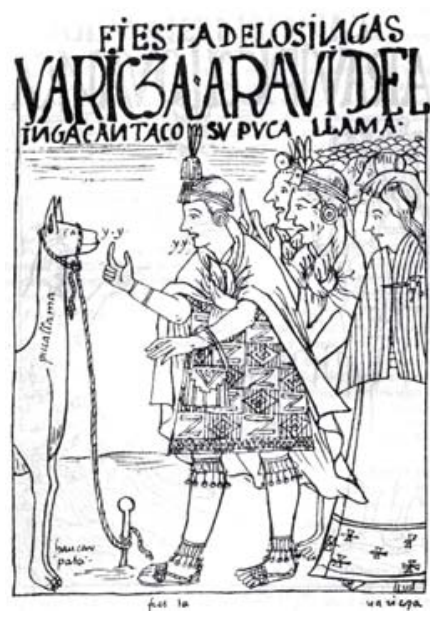

Figura $\mathrm{N}^{\mathrm{o}} 1$ 
Fiesta. Uaricza, araui del Inga. Las fiestas cantar y bailar, uaricza, que cantaron puca llama, al tono del carnero cantan, dice así: con compás, muy poco a poco, media hora dice $\mathrm{y}-\mathrm{y}-\mathrm{y}$, al tono del carnero, comienza el inga como el carnero dice, y está diciendo yn. Lleva ese tono y de allí comenzando va diciendo sus coplas, muy muchas responden las coyas y ñustas, cantan a voz alta, muy suavemente (Guamán Poma, 1615/19).

La palabra poética entonces aparece inserta en un contexto diferente, lo es en tanto se asocia a sus contextos de producción, en especial, a su modulación ritual. Esto nos lleva a la desterritorialización de los textos quechuas. Para Guamán Poma la producción "poética» no es un quehacer localizado y exclusivo de los espacios señoriales incas, así se explica que en las distantes y diversas poblaciones tiene lugar las expresiones propias de cada región. Esta última característica no solo está nominada sino identificada como formas indígenas: «De manera que las cuatro partes tienen sus vocablos y taquies y los Quichiuas, Aymarays y Collas, Soras y algunos Condes tienen un vocablo; y así». (Guamán Poma: 245, f. 327-329) Me refiero a las variedades de formas que se producen en todas las regiones (Beyersdorff, 1986; Husson, 1993 y 2002), diversidad que a su vez las vincula a los instrumentos que en aquellas regiones se utilizan: «El araui y canción lastimosa que cantan las ñustas y los mozos tocan el pingollo». Mejor definida en la secuencia texto-instrumento musical-usuario-danza:

Es que llama taqui, cachiua, haylli, araui de las mozas, pingollo de los mozos; y fiesta de los pastores llama miches, llamaya; y de los labradores pachaca harauayo; y de los collas quirquina collina aymarana; de las mozas guanca; de los mozos quena quena; en estos huelgos que tiene cada ayllo y parcialidad de este reino. (Guamán Poma: 239, f. 315-318)

La propuesta de Guamán Poma tiene relación con su postura irreverente frente a la autoridad, de manera que la creación-producción textual no es privativa de las élites, si no de las diversas esferas de la sociedad indígena:

Capítulo primero de las fiestas, pascuas, y danzas taquies de los Ingas, y de cápac apocopas y principales, y de los indios comunes de estos reinos, de los Chinchaysuyos, Andesuyos, Collasuyos, Condesuyos, las cuales danzas y arauis no tienen cosa de hechicería, ni idolatría ni encantamiento, si no hubiese borrachera sería cosa linda. (Ibídem)

Pero a diferencia del Inca Garcilaso, Guamán Poma propone que aquello que identificamos como creación poética, además de pertenecer 
a un calendario ritual, está relacionado a prácticas que realizan diversos segmentos de la sociedad indígena. Así, entonces, conviene tener en cuenta las dos dimensiones que de la Nueva coronica se derivan: asumir que la textualidad quechua se inserta en un programa narrativo mayor que llamaré evento y que esta textualidad a su vez tiene sus propias estrategias y semántica. La etnopoética, en ese sentido, permite advertir que las repeticiones que se aprecian en las lenguas aglutinantes como el quechua o el aymara no tienen que ver con la métrica y la rima sino con la construcción de sentidos, esto porque lo que importa, a nivel textual, es cómo se dice y qué se desea decir, por eso interesa detenerse, en la poesía quechua, en las estructuras paralelas o los dísticos semánticos (Mannhein, 2002, 1987, 1986; Espino 2001) que arma el fluir del discurso.

\section{Anchorena: Imaginando la poesía quechua}

La Gramática Quechua de José Dionisio Anchorena, publicada por la Imprenta del Estado en 1874, dedica todo una sección al análisis de la poesía quechua. Antes lo habían hecho Mariano Eduardo Rivero y Juan Diego Tschudi en Antiguedades peruanas (1851) y Asciclo Villarán en $L a$ poesía en el imperio de los incas (1873) (Espino, 1999 y 2004). El modelo que opera está inspirado en el Inca Garcilaso de la Vega y se asocia a las propias retóricas hispanas, por eso Anchorena remarca el cómputo de versos y rimas. Cuestión que vista desde el canon del siglo xix era la forma como se podía abordar los asuntos de la poesía. Jean-Philippe Husson (2002) exagera su critica al trabajo de José Dionisio Anchorena, por la «falta de pertinencia» al utilizar como criterios «la rima y el cómputo silábico» y la "extremada imprecisión de sus definiciones» (2002:401). Considero que Husson no contextualiza los procesos a pesar de su indagación diacrónica e interesante, cuando identifica a los dísticos semánticos como uno de los elementos definitorios de la poesía quechua. Hay en su trabajo un error metodológico: construir su edificio sobre dos columnas imaginarias: los poemas recogidos por el cronista indio Felipe Guamán Poma de Ayala, a partir de las noticias de 1908 y recién conocida por la edición facsimilar de 1936, y los textos sacros que César Itier ha divulgado. Olvida que el contexto de realización de estos textos tiene 
como horizonte lo que llamé en 1996 la «inclusión andina», es decir, la afirmación de una de las corrientes que imagina a la nación con el componente indígena.

De esa suerte el modelo poético no tiene otro objeto que aquel que deviene de una de las fuentes de imaginación de la nación andina: los Comentarios Reales de los Incas. Estos desplazamientos consideran: uno, la necesidad de explicar la naturaleza de la producción textual quechua, que de cuenta de la virtuosidad y plasticidad de la palabra india, evidenciada en las traducciones que con creces cumple Anchorena; dos, el modelo de equivalencias se comporta como una suerte de universal aplicable: la analogía es posible tal como lo había imaginado el Inca Garcilaso, la equipara ción es posible sobre la base de las formas prestigiadas, es decir, una equivalencia retórica entre textos quechuas con textos hispanos. Tres: pero esta analogía a pesar de la insistencia en formas de la combinación versal, la sucesión de rimas (asonantes, consonantes o libres) y las combinaciones estróficas de tal o cual cualidad, simultáneamente, proponía la naturaleza de los textos. Ninguno de los textos quechuas queda fuera de esa lógica utilitaria o ritual. Sin desearlo, la Gramática Quechua, al describir tales textos sugiere las formas que utilizaban (lugares y momentos en que estos ocurrían y los narratarios); por eso, será una suerte de levantamiento del estado de la cuestión. Ubicada la función de cada manifestación oral, ahora fijada en el blanco y negro del impreso, que nos llega como legado imperecedero.

La Gramática Quechua de José Dionisio Anchorena comienza con una afirmación retórica: «Para la formación del verso debe atenderse principalmente al ritmo, al metro y á la rima». (119)³ Revisará, así, cada una de las características formales; para tal efecto, acusa traducciones de Garcilaso, F. Rioja, F. de Aguilar, F. de la Torre, Espronceda, Renjifo, Quevedo, M. Chacel, Fr. L. de León, T. Irriarte y, entre sus connacionales, a Corpancho, Bermudez de C. , J. F. Larriva; amén de la traducción del Himno Nacional, «Pakarinak huaylli / Huani» (124-127). Luego de esta exploración a la retórica autorizada ingresa a presentar la poesía que llama inca:

La poesía fue conocida y cultivada en el Perú desde los primeros Incas ó emperadores que impulsaron su progreso y perfeccionamiento disponiendo su enseñanza en las escuelas de instrucción. [...] 


\begin{abstract}
Las composiciones especiales del quechua, son: el harahui ó yarahui, el huaynu o huañu, el haylli, el huacaylli y huaylli, la huayllia, el ayataqui y huaccataqui, el huancay y aranhuay y otras varias de ménos interes. Todas ellas destinadas al canto a excepcion de las dramáticas. Hay tambien otras de las clases de yarahui llamadas mestizos o amestizados porque se componen de versos quechuas combinados con españoles (130-131).
\end{abstract}

Anchorena es fedatario de las propuestas del Inca Garcilaso. Discute el asunto de la escritura, recuerda que "se desconocía en el pais el empleo de las letras» y "que los quipus no eran suficiente al efecto sin la tradición oral, [por lo que] se hizo cada vez mas necesaria la poesía» (131). Luego establece las formas que se divulgan en los Andes. A partir de aquí establece su aproximación a la poesía quechua que él registra; por lo que pasa ahora de las formas autorizadas a formas que busca difundir -y autorizar- en la ciudad letrada. Para Anchorena estas son las formas más comunes de la poesía quechua:

1. Harahui o Yarahui: "Su argumento, en uno y otros casos se refiere siempre a las afecciones más tiernas y sentimentales referentes a sí mismo o al objeto amado». (131) Consigna Icma, «La viuda» del Dr. Tirado; Chaymaycuna, «Las quejas» de Melgar; y, Chikiyok, «El desgraciado» del Dr. Aranda.

2. «El huaynu o huayñu es una poesía ligera», e indica que «El tema de huaynu es el mismo del yarahui y tambien se canta después de este en las serenatas». (134) Incluye, "Quita urpi», La paloma agreste; «Chincachicui», La perdida; y, «Ripucui», La ausencia.

3. Haylli está caracterizado porque después de uno, o dos, versos «se repite en coro la palabra haylli triunfo, viva o vitor». (135) «Su tema es para festejar la entrada triunfal de las personas ó cosas destinadas a objetos de estima o para animar al trabajo. Así, cantan las siguientes: la primera [Malquipak] conduciendo árboles para los altares de las procesiones religiosas y la segunda [Yarkapak] en la cava de las acequias del comun del pueblo». (135-136) Reproduce Malquipak, "A la planta»; y, Yarkapak, "A la acequia».

4. El huacaylli o huaylli "son las composiciones líricas más serias del quechua». El huacaylli «es el himno para enzarzar a la Divinidad». (136-137) Para el huaylli distingue dos modalidades: a) Aquella que se asemeja a la canción real o romance heroica y se utiliza «cuando se forma para cantar las grandes hazañas y los acontecimientos 
notables». (137); y, b) «en asuntos de menor interes, corresponde a la canción común y puede llevar metro menor». (137) Incluye Huacaylli, «Himno»; Sumak ñusta, «Hermosa Ninfa» de Garcilaso Inca; y, Mana kakmanta cachispa, "A un dios imitas» de M.M. Basagoyta.

5. "La huayllia es una variedad de huaylli o más bien el mismo, en composiciones pequeñas y aplicadas a cierto objeto, como es la cantinela o cantata resepecto á la canción: se compone de cuartetas o quintillas de versos de seis a ocho sílabas asonantes o consonantes» (139) Consigna Huayllia, "Cantinela».

6. "Los cantares denominados ayataqui y huaccataqui constan, el primero de versos de ocho a diez sílabas en cuartetos libres o asonantes de varias estrofas que se cantan en tono lúgubre y melancóloco en las exequias de los finados, haciendo una relacion de su vida y virtudes y manifestando el profundo sentimiento que causa su muerte. Son una verdadera necrología elegíaca». (139-140) El huaccataqui «es de versos asonantes ó libres de diez a doce silabas en cuartetas o quintillas que forman pequeñas canciones pastoriles sobre los ganados y vida del campo, especie de bucólicas de tono fijo que se cantan cuando se señalan los ganados: consigna «Ayataqui», «Cantar fúnebre»y «Huaccataqui», «Cantar pastoril». (140)

7. «El huancay y aranhuay son poesías dramáticas, que no se cantan, correspondiente primero a la tragedia y el segundo a la comedia y se compone de versos sueltos o asonantes de ocho a diez sílabas. Entre los dramas más notables del quechua, el de Ollanta, Uscapaukar, la muerte del Atahualpa, la de Titu cusi yupanqui y otros pequeños que aun se representan en algunos pueblos del interior, en las octavas del Corpus Cristi e invencion de la Cruz». (140-141)

8. «Las composiciones denominadas mestizas o amestizados son: el yarahui o huaynu, cuyas estrofas se forman alternando versos quechuas y españoles». (141) De estas incluye en texto aquella que comienza con Maytan rinqui maypin camquis y Causa de mi tormento. Como podrá advertirse, Anchorena tiene una especial preocupación por remitir al pasado remoto de los Incas. Son los incas los poseedores de esas formas que el desea consignar. Pero en los tiempos actuales, en el siglo xix, muchos de estos textos estaban despareciendo. Este es 
el caso del haylli y huaccaylli. "Estas canciones de uno y otro género, del tiempo de los Incas, han desaparecido casi del todo; pues el conquistador cuidó lo bastante que no se conservaran ni se cantaran los himnos al sol para evitar la idolatría; ni tampoco los otros para que no hubiera recuerdo de los Incas». (137) En cambio, da cuenta de los nuevos procesos poéticos y dramáticos: (1) La ascendencia del yaraví y las formas mestizas que han sido una constante contemporáneamente hasta casi localizar sus funciones en escenarios rituales y en el calendario comunal, y confundir de manera genérica cualquier forma indígena con la del huayno en general. (2) La presencia de especies dramáticas (wamka) que no se consignaban en el canon. Este es el caso de La Muerte del Inca Atahualpa referida en relación a los rituales que en el interior de los pueblos andinos, por entonces continuaban, produciéndose. He allí el aporte señero y el coraje de un hombre que había viajado por todo el país, y quien dentro de un espíritu cívico, ofrecía un programa civilizatorio que suponía el diálogo de culturas y no sólo la comparación episódica como pretende ver Husson.

\section{Notas}

1 El presente trabajo es parte de mi tesis doctoral Etnopoética quechua / Texto y tradición oral quechua (2006).

2 Esto en referencia a la recepción del texto, a su estudio y divulgación en la comunidad académica y su incorporación en el imaginario letrado de los países andinos. De hecho hay que recordar las noticias 1908 y la publicación del manuscrito en 1936.

3 Me estoy refiriendo a su «Lección Décima: De la versificación» (1874: 118-141).

\section{Referencias bibliográficas}

ANCHORENA, José Dionisio (1874): Gramática quechua ó del idioma del imperio de los Incas. Imp. del Estado, Lima.

ARGUEDAS, José María (1949): Canciones y cuentos del pueblo quechua. Selección y traducción de José María Arguedas y José Mará Benigno Farfán, Edit. Huascarán, Cantos y cuentos quechuas. Lima Munilibros, Municipalidad de Lima Metropolitana, 1986, II, pp. 93-109 (Munilibros 12 y 13).

—— César Miró, Sebastián Salazar Bondy (1986): Ollantay, cantos y narraciones quechuas. Versiones de... Lima, Eds. Peisa. 
BASADRE, Jorge (Comp.) (1938): Literatura inca. Selección de... Introducción general de Ventura García Calderón, Brouwer de Desclée, París (Biblioteca de Cultura Peruana, Primera Serie, No 1).

BENDEZÚ AYBAR, Edmundo (1980): Literatura quechua. Prólogo y edición de... $2^{\text {a }}$ ed., Fondo Editorial Universidad Ricardo Palma, Lima, 2003.

BEYERSDORFF, Margot (1986): «La tradición oral quechua vista desde la perspectiva de la literatura». En Revista Andina, № 1 , Cusco, pp. 213-236.

ESPINO RELUCÉ, Gonzalo (2004): Adolfo Vienrich, la inclusión andina y la literatura quechua. Universidad Ricardo Palma, Lima,

— (1999): Imágenes de la inclusión andina. Literatura peruana del XIX. Instituto de Investigaciones Humanísticas - Universidad Nacional Mayor de San Marcos, Lima.

FLORIÁN, Mario (1980): La épika inkaica. Lima.

GARCILASO DE LA VEGA, Inca (1609 / 1985): Comentarios reales de los incas. Primera Parte. Prólogo de Aurelio Miró S.; bibliografía de Alberto Tauro y edición de César Pacheco Vélez. Banco de Crédito del Perú, Lima.

GUAMÁN POMA DE AYALA, Felipe (h. 1615): Nueva coronica y buen gobierno. Fondo de Cultura Económica, México, 1993.

HARRISON, Regina (1996). Entre el tronar épico y el llanto elegíaco. Simbología indígena en la poesía ecuatoriana de los siglos XIXXX, Ed. Abya-yala - Universidad Andina Simón Bolívar, Quito.

HUSSON, Jean-Philippe (2002): Literatura quechua. En Boletín del Instituto Riva-Agüero, BIRA, № 29, Pontificia Universidad Católica del Perú, Lima, pp. 387-522.

(1993): «La poesía quechua prehispánica / Su reglas - Sus categorías - Sus temas. A través de los poemas de transcritos por Waman Poma de Ayala. En Revista de Crítica Literaria Latinoamericana, año XIX, $\mathrm{N}^{\mathrm{o}} 37,1^{\mathrm{er}}$ semestre, Lima, pp. 63-85.

LAEB Programa de Linguíística Andina y Educación Bilingüe (2003): Canciones indígenas de los andes ecuatoriano / El ayllu y el ciclo agrícola. Pueblos Indígenas y Educación, Ed. Abya Yala - LAEB Linguística Andina y Educación Bilinguie (Universidad de Cuenca), Quito, 1996. (Pueblos Indígenas y Educación, No 35-36, juliodiciembre de 1996). 
LEÓN-PORTILLA, Miguel (1996): El destino de la palabra. De la oralidad y los códice mesoamericanos a la escritura alfabética. Fondo de Cultura Económica, México.

LIENHARD, Martin (1988): «Arte verbal quechua e historiografía literaria en el Perú». En Schweizerische Amerikanisten - Gesellschaft. Bull. 52, pp. 49-56.

MANNHEIM, Bruce (2003): «Paralelismo quechua, sentidos de la palabra y análisis cultural». En Lhymen $\mathrm{N}^{\circ}$ 2, Lima, pp. 11-58 (ante del título: «Ritmo y no la síbala deben ser tomado en cuenta»).

NAGY, Silvia M. (1994): «Juan Wallaparrimachi, el poeta de la ausencia». En Signo, Cuadernos Bolivianos de Cultura, № 41, La Paz, pp. 7-32.

ROMUALDO, Alejandro (seud.) (1984): Poesía aborigen y tradicional popular. Prólogo, selección y notas de... Ed. Edubanco, Lima, (Poesía Peruana Antología General, t. I).

VALLADARES QUIJANO, Manuel (2005): «Las letras que forjaron el indigenismo cusqueño». En Guaca № 2, Lima, pp. 39-60.

VIENRICH, Adolfo (1905 / 1999): Tarmap Pacha-Huaray / Azucenas Quechuas (Nuna-shimi chihuanhaui). Bilinguie, Imp. La Aurora de Tarma, 1905; CXXIV, 131 pp. [Seudónimo: Unos Parias; antes del título: Tarmap Pacha-Huaray; al final del prólogo: Pumacahua / Tarma, 27 de octubre de 1905]. $2^{\text {a }}$ ed., nota preliminar de Pedro Díaz Ortiz. Tarma, 99 Concejo Provincial de Tarma, 1956; 109 pp. $3^{\text {ra }}$ ed., nota preliminar de Pedro Díaz Ortiz. Huancayo, Casa de la Cultura de Junín (Biblioteca Huanca 2), s/a, 109 pp. $4^{\text {a }}$ ed. Azucenas y fábulas quechuas. Edición de Pedro Díaz Ortiz, Universidad Ricardo Palma, Lima, 1999.

VILLARÁN, Acisclo (1874): «La poesía en el Imperio de los Incas; ensayo histórico. Dedicada en muestra de gratitud al eminente literato D. Eduardo Asquerino». En El Correo del Perú, Lima, 1873-1874 [Inserto entre los $\mathrm{N}^{\circ}$ ix al li, 1873 y ii al xiv, 1874]. 